\title{
EXPERIMENTAL RESEARCHES REGARDING ASSESSMENT OF COVERAGE DEGREE OBTAINED BY ORCHARD SPRAYING MACHINE
}

\author{
Marin Eugen, Matache Mihai, Nitu Mihaela, Gheorghe Gabriel \\ National Institute of Research - Development for Machines and \\ Installations Designed to Agriculture and Food Industry, Romania \\ rosumihaelan@yahoo.com
}

\begin{abstract}
For general good health and state of wellbeing, most of us like to consume fruits in fresh state as well as fruit products previously processed. Quality and appearance of fruits in general is closely related to the health of the orchard trees they are provided from. These trees have to be fed and taken care of in order to produce high yields with best quality fruits. An innovative practice to give them the needed nutrients is to use foliar fertilization. Thus, by applying this type of treatment, it is aimed to reduce the used substances quantity simultaneously with increasing the treatment efficiency. These issues are closely depending on the tree leaf covering degree with droplets, meaning that higher and even coverage assures better nutrient absorption. This parameter is dependent on the working pressure, the flow of liquids, the type of the nozzle as well as the working speed of the equipment used. Within the paper there are presented the experimental researches performed in order to assess the influence of the working parameters on the covering degree of the fertilization substances. The experiments were performed in laboratory conditions, using a specialized stand, designed especially for simulation of the tree height levels and the vehicle speed. The stand was fitted with water-sensitive material, which maintained the initial position and form of the sprayed droplets. Latter on, high resolution pictures of the material were taken and then analysed using custom designed vision software. The analysis results represented the covering degree. The experiments were performed for various instances that the equipment can perform: fan on and off, different working pressures and different distances until the tree and the results were compared.
\end{abstract}

Keywords: spraying machines, distribution uniformity, pressure, protection.

\section{Introduction}

Orchard yield is influenced by the applied technologies level, foliar fertilization being an important branch of these. Usage of fertilizers is still one of the most important means to increase production and ensure costs efficiency in horticulture.

Generally, the main objective of foliar fertilization is to assure maximum adsorption at the leaf level and reduce the soil spillage. Environment protection issues have occurred since the late nineteenth century, although we cannot talk about farming without reference to its consequences on the environment [1].

During the working process of orchard spraying machines, a part of the fertilizer is lost due to existing gaps between the trees and because of the drift of dispersed liquid droplets. In consequence, a part of the used fertilizer remains in atmosphere, on soil and on neighbourhood plantations $[2 ; 3]$.

The main objective of a foliar fertilization work is to evenly store a maximum quantity of fertilizer on the trees leaves, in order to assure maximum adsorption.

Spraying represents the decomposition process of a liquid jet in small-diameter droplets of various sizes, the average diameter of the resulting droplets ranging from several microns to the maximum size of $3 \mathrm{~mm}$. [4;5].

The spray jet has been studied by many researchers [6;7], concluding that the surface of the jet flow exiting a nozzle orifice is subject to small disturbances. These disturbances are generated by several parameters like the flow regime, frictional forces, pump pressure, nozzle diameter, gas bubbles in fluid etc.

Within the paper the experimental researches are presented performed on foliar fertilizing equipment in order to assess the covering degree with fertilization substances. Within the paper experiments for various instances that the equipment can perform are presented: fan on and off, different working pressures and different distances until the tree and the results were compared.

\section{Materials and methods}

Droplets produced through the nozzles of one sprayer do not have a uniform size. The nozzle jet contains liquid particles of different sizes, which appear in function of the particular parameters of the 
spraying process: liquid characteristics, nozzle type, working pressure etc. The coverage degree is influenced by the droplet size, achieving higher values as the droplet size decreases.

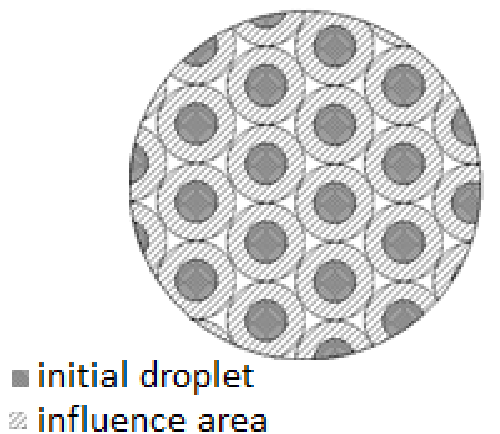

Fig. 1. Ideal distribution of droplets under a nozzle jet cone and influence zone of a droplet [8]

For hydraulic nozzles, there is dependence between the working pressure of the nozzle and the droplets spectrum. A higher working pressure implies apparition of smaller diameter droplets, thus obtaining higher coverage degrees.

Considering that the droplet shape is spherical (Figure 2) and that droplets form hemispheres on the leaf surface, the contact surface on the foliar system is equal with the equatorial section surface of the sphere surface. Further, in a volume $\mathrm{V}$ of liquid (m3), $\mathrm{Z}$ droplets of d diameter $(\mathrm{m})$ can be obtained, according to (1):

$$
Z=\frac{6 V}{\pi d^{3}}
$$

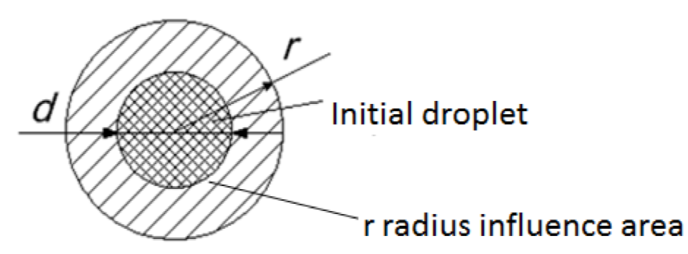

Fig. 2. Influence area of a droplet [1]

Considering that every drop is surrounded by an area of influence with "r" radius (m), the area covered by the $\mathrm{Z}$ drops will be:

$$
A_{\text {covered }}=Z \cdot A_{\text {influence }}=\frac{3 V r^{2}}{d^{3}}[9] .
$$

However, in practice the coverage degree is much smaller than the theoretical calculated one. In order to directly measure the coverage degree of the foliar fertilization spraying machine in orchards with a vision system, we used as fertilizer a solution of water and methylene blue as the colouring agent. Then, for the experiments a stand was used composed of a water-sensitive material mounted on a trolley (Figure 3), which was moving on two rails and it was driven by an electric engine with belt transmission. The trolley passed on besides the orchard spraying machine with constant speed (2 $\mathrm{m} / \mathrm{sec}$ ), simulating passing of the spraying machine between the orchard rows of trees and performing three repetitions for each working pressure, respectively 10,15 and 20 bars. Also, the stand was mounted at 1 , respectively $2 \mathrm{~m}$ away from the spraying machine. For the experiments we used a carried orchard spraying machine with 10 nozzles of $0.3 \mathrm{~mm}$ diameter endowed with a fan. 


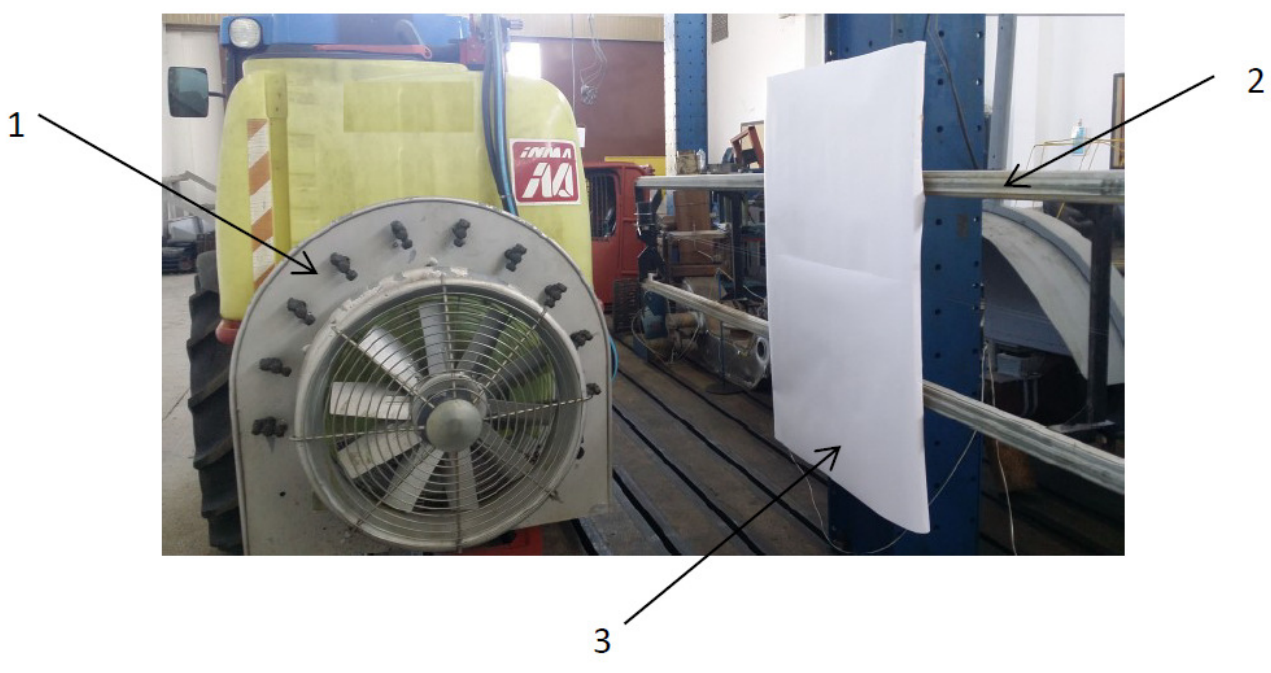

Fig. 3. Stand for simulation of the spraying machine passing between the rows in orchards: 1 - orchard spraying machine, 2 - testing stand with rails, 3 - water-sensitive material mounted on a trolley

The following steps were followed during the tests:

- loading the spraying machine tank with the water-methylene blue solution;

- installing the same type of nozzles (nozzle $=0.3 \mathrm{~mm}$ ) spraying machine;

- mounting the water-sensitive capture surface for droplets on trolley support;

- setting the working pressure and distance until the spraying machine;

- starting the sprayer machine and trolley, simulating the machine passing between the rows of trees.

After these steps, high resolution images were taken for the capture surface (4962x7019 pixels) using an EPSON L220 scanner, for each testing instance. These pictures were then processed using vision software for the coverage degree and the number of droplet assessment. For image processing, first the contrast was increased between the droplet colour (blue) and the background (white). Then the blue pixels were extracted from the pictures and the images were converted to grayscale. Following, it a threshold was set for pixel intensity and the surface coverage assessed with pixels over the threshold, which represented the surface covered with droplets. Afterwards we counted the number of droplets per surface units, having as reference the main diameter, which was larger than one pixel ( 1 pixel $=45$ $\mu$ ), considering two linked droplets as only one, if they were smaller than a pixel. The droplets were counted on $1 \mathrm{~cm} 2$ surfaces.

\section{Results and discussion}

The scanned pictures for each experiment were analysed using NI Vision Builder Inspection software. Following, we presented a set of measurements made for the experiment performed at $10 \mathrm{bar}$ pressure test, at $1 \mathrm{~m}$ between the stand and the spraying machine, with the fan OFF, at a working speed of $2 \mathrm{~m} \cdot \mathrm{s}^{-1}$. In Figure 4 is the initial scanned picture of the droplets on the water-sensitive material presented, without any processing.

In Figure 5 the same image is presented after grayscaling with extraction of the blue plane from the initial image. Also, we adjusted the contrast between the background and the blue coloured droplets. In Figure 6 there is presented a section of Figure 5, in which with blue colour the pixels corresponding to the impressions of droplets on the water-sensitive material are shown. The pixels were highlighted after setting a threshold of $25 \%$ between the background pixel intensity and the pixels corresponding to droplets. The threshold value was chosen after initial calibration with an artificial made image with known values. One can compare Figures 5 and 6 , and notice that the shape of the droplets is almost identical, the differences being generated by the calibration value for the threshold intensity. Then the coverage degree was simply assed after counting the pixels with grayscale intensity over the threshold and reporting them to the entire investigated surface. 


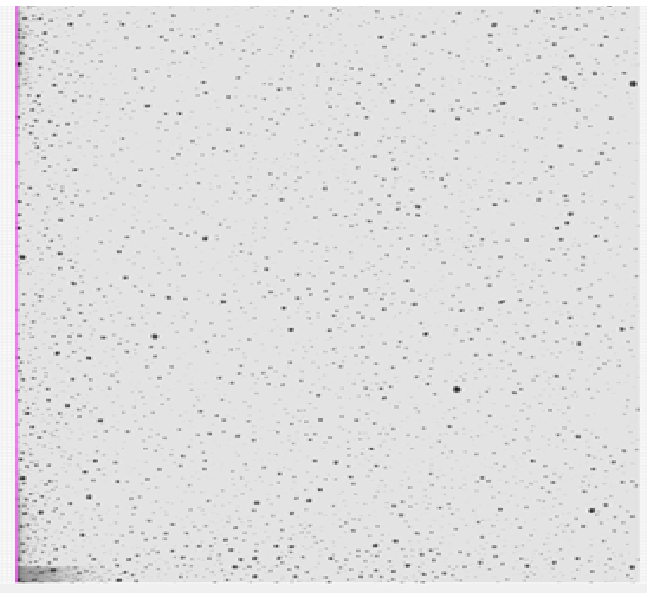

Fig. 4. Raw image of droplets for working pressure of 10 bars

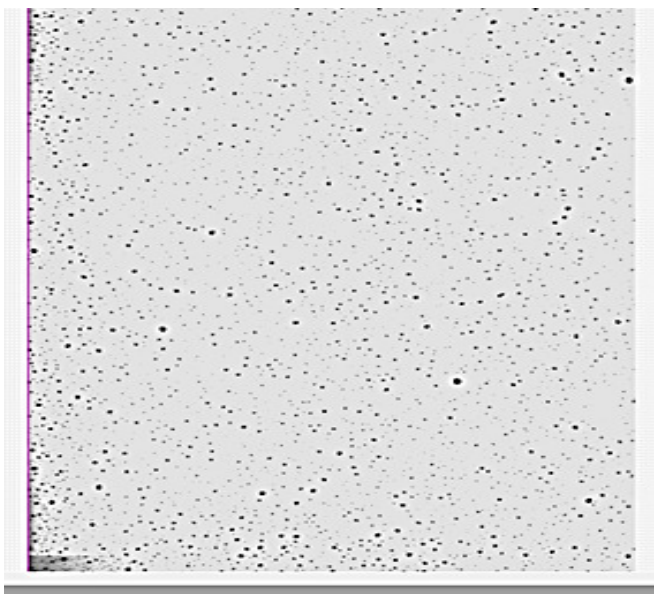

Fig. 5. Grayscale image of droplets for working pressure of 10 bars

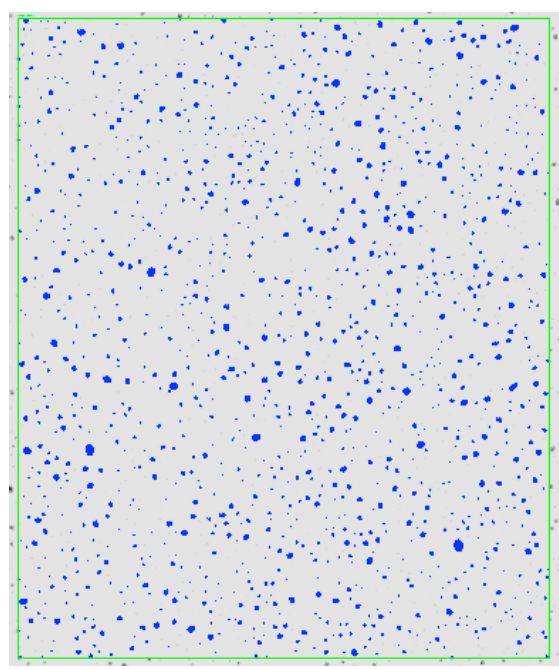

Fig. 6. Coverage degree evaluation by counting blue pixels surface

Observing the obtained results from Table 1, it is shown that the coverage degree increases with the working pressure as well as with increasing the distance from the spraying machine to the trees. Also, the fan has an important role in obtaining a higher coverage degree.

Table 1

\section{Coverage degree for different working parameters}

\begin{tabular}{|c|c|c|c|c|}
\hline $\begin{array}{c}\text { Crt } \\
\text { no }\end{array}$ & $\begin{array}{c}\text { Working } \\
\text { pressure (bar) }\end{array}$ & $\begin{array}{c}\text { Fan } \\
(\text { ON/OFF })\end{array}$ & $\begin{array}{c}\text { Distance between } \\
\text { stand and spraying } \\
\text { machine (m) }\end{array}$ & $\begin{array}{c}\text { Coverage degree } \\
\mathbf{( \% )}\end{array}$ \\
\hline 1 & 10 & ON & 1 & 19.3 \\
\hline 2 & 10 & ON & 2 & 23.2 \\
\hline 3 & 10 & OFF & 1 & 18.5 \\
\hline 4 & 10 & OFF & 2 & 19.2 \\
\hline 5 & 15 & ON & 1 & 29.6 \\
\hline 6 & 15 & ON & 2 & 32.5 \\
\hline 7 & 15 & OFF & 1 & 27.3 \\
\hline 8 & 15 & OFF & 2 & 25.4 \\
\hline 9 & 20 & ON & 1 & 44.4 \\
\hline 10 & 20 & ON & 2 & 48.1 \\
\hline 11 & 20 & OFF & 1 & 40.2 \\
\hline 12 & 20 & OFF & 2 & 38.1 \\
\hline
\end{tabular}




\section{Conclusions}

Coverage degree increases with the working pressure as well as with increasing the distance from the spraying machine to the trees and fan has an important role in obtaining a higher coverage degree.

The testing stand permitted simulation of the working process of a spraying machine in different situations. However, it has limitations, especially from the measuring surface point of view, which was flat. In real life situation, leaves do not have a flat surface, the tree canopy being irregular. We accepted these limitations making the assumption that the purpose of the paper was to compare the performance obtained by the spraying machine in different working instances.

\section{Acknowledgement}

This work was funded by the Executive Agency for Higher Education, Research, Development and Innovation Funding, within the project entitled "PN 162402 01: "Innovative technology for the maintenance of tree plantations situated in rural areas through soil works, root cuts and precision foliar fertilization", ctr. 8N/09.03.2016 / Ad. no. 1/2017.

\section{References}

1. Stahli W., Bungescu S., Apparata. Equipment and machines for plant protection, AGROPRINT USAMVBT Publishing House, Timişoara 2006.

2. Ennis W. B., Ralph E., Williamson K. P. and Dorschner. Studies on Spray Retention by Leaves of Different Plants, Vol. 1, No. 3 (Apr., 1952), pp. 274-286.

3. Foqué D., Pieters Jan G., Nuyttens D. Spray deposition and distribution in a bay laurel crop as affected by nozzle type, air assistance and spray direction when using vertical spray booms, Crop Protection vol. 41, 2012, pg. 77-87.

4. Hess F. D. and Falk R. H. Herbicide Deposition on Leaf Surfaces, Vol. 38, No. 3 (May, 1990), pp. 280-288.

5. Patel M. K., Sahoo H. K., Nayak M. K., Ghanshyam C. Plausibility of variable coverage high range spraying: Experimental studies of an externally air-assisted electrostatic nozzle, Computers and Electronics in Agriculture 127, 2016, pp. 641-651.

6. Heidarya M. Al, Douzalsa J.P., Sinfortb C., Vallet A. Influence of spray characteristics on potential spray drift of field crop sprayers: A literature review, Crop Protection, Volume 63, 2014, pp. 120-130.

7. Mihăiţă A. Efficiency of the phytosanitary treatments in fruit agrosystems / Eficientizarea tratamentelor fitosanitare în agrosistemele pomicole, Doctoral thesis/Teza de doctorat, USAMV Bucharest, 2003.

8. Popescu M. Researches regarding to optimization of the qualitative indices of work of spraying machines in crop field/Cercetări privind optimizarea indicilor calitativi de lucru ai maşinilor de stropit culturile de câmp, Doctoral thesis/Teză de doctorat, Transylvania University Braşov, 2007.

9. Roşu (Niţu M.), Căsăndroiu T., Matache M., Cujbescu D., Vlăduţ V., Sorică E. Researches regarding the influence of the nozzle working pressure on spraying machines distribution uniformity, Influence of the jet's angle size on the spraying process, Proceedings of the international symposium ISB-INMA TEH "agricultural and mechanical engineering", ISSN 2537 $-3773,2016$, pp. 661-668. 